\title{
Potential distribution of the primary malaria vector Anopheles gambiae Giles [Diptera: Culicidae] in Southwest Nigeria under current and future climatic conditions
}

Isaac Omotayo Olabimi ${ }^{*}$ (D), Kayode David lleke², Babasola Williams Adu² and Temitope Emmanuel Arotolu ${ }^{3}$

\begin{abstract}
Background: Mosquitoes are key vectors for the transmission of several diseases. Anopheles gambiae is known to transmit pathogens of malaria and filariasis. Due to several anthropogenic factors such as climate change and population growth leading to diverse land use, their distribution and disease spreading pattern may change. This study estimated the potential distribution and climatic suitability of An. gambiae under the present-day and future conditions across Southwest Nigeria using Ecological Niche Modelling (ENM). The future scenarios assessed were based on two general circulation models (GCMs), namely community climate system model 4 (CCSM4) and geophysical fluid dynamics laboratory-climate model 3 (GFDL-CM3), in two representative concentration pathways (RCP 2.6 and RCP 8.5).

Methodology: The occurrence data were obtained from literatures that have reported the presence of An. gambiae mosquito species in locations within the study area. Ecological niche modelling data were processed and analysed using maximum entropy algorithm implemented in MaxEnt.

Result: Fifty-five (55) unique occurrences of An. gambiae were used in the model calibration after data cleaning. Data analysis for the present-day habitat suitability shows that more than two-thirds (81.71\%) of the study area was observed to be suitable for An. gambiae population. However, the two future GCMs showed contrasting results. The CCSM4 models indicated a slight increase in both RCPs with 2.5 and 8.5 having 81.77 and $82.34 \%$ suitability, respectively. The reverse was the case for the GFDL-CM3 models as RCPs 2.5 and 8.5 had 78.86 and $76.86 \%$.

Conclusion: This study revealed that the study area is climatically suitable for An. gambiae and will continue to be so in the future irrespective of the contrasting results from the GCMs used. Since vector population is often linked with their disease transmission capacity, proper measures must be put in place to mitigate disease incidences associated with the activities of An. gambiae.
\end{abstract}

Keywords: Anopheles gambiae, Southwest Nigeria, Ecological Niche modelling, Climate change, Climatic suitability

*Correspondence: isaacolabimi@gmail.com

1 Environmental Biology and Public Health Unit, Department of Biology, School of Science, Federal University of Technology, Ondo State, P. M. B. 704, Akure, Nigeria

Full list of author information is available at the end of the article

\section{Background}

Mosquitoes are seen as a threat in different climes because they are vectors of several pathogens alongside their annoying sounds and bites. These pathogens cause a variety of public health diseases, including dengue fever, malaria, filariasis encephalitis, chikungunya fever, West Nile virus and Zika virus, among other diseases (Anupam 
et al., 2012). Due to the disease burden associated with these mosquito species, there is a need to monitor their populations effectively. The means by which this can be done is to use a variety of tools summing up as Ecological Niche Modelling (ENM). The ability of a particular organism to thrive in a particular habitat depends on the interaction of space and time between it and the environment (Brown et al., 1995). Ecological niche modelling (ENM) is an ecological tool that uses computer algorithms to predict species distribution across geographical space and time using environmental variables (Harrison, 1997; Peterson et al., 1999). It is useful in the characterisation of species in an area that is determined by environmental factors, i.e. those factors that are precisely responsible for the geographical distribution of the species' (Grinnell, 1917; Peterson, 2006). The use of ENM in environmental research has been greatly enhanced due to recent developments in geographic information systems (GIS) and increased availability of detailed geospatial environmental data, including remote sensing data (Guisan \& Zimmermann, 2000). The procedures involved in ENM enable ecologists to find answers to questions bordering on which environmental variables (e.g. temperature, precipitation, digital elevation, land cover, land use, etc.) are responsible for the distribution of the observed species that can be used to contrast the niches of various species (Hawkins et al., 2003; Kremen et al., 2008). Quantitative modelling approaches based on ecological niche theory are mainly applied to understanding the relationship between species and the environment (Lestina et al., 2016). Ecological niche modelling predicts the distribution of a species by using the occurrence data of that particular species alongside selected environmental variables to model the niche of a species in an environment that is then projected into a geographical space (Elith et al., 2006). Anopheles gambiae is responsible for the transmission of malaria and lymphatic filariasis (CDC, 2019; WHO, 2007, 2010). Malaria is an acute febrile disease caused by the protozoan parasite Plasmodium, which is transmitted through the bites of female Anopheles mosquitoes (WHO, 2007). Over 219 million cases of malaria were reported in 87 countries in 2017 (WHO, 2019a). Four major human malaria parasites are known in Africa, namely $P$. falciparum, $P$. vivax, $P$. malariae and P. ovale (Abose et al., 1998; WHO, 2019a). Lymphatic filariasis, commonly referred to as elephantiasis, is a neglected tropical disease that occurs when filarial parasites are transmitted to humans through mosquitoes (WHO, 2019b). In 2018, 893 million people in 49 countries around the world are still at risk of lymphatic filariasis (WHO, 2019b). Wuchereria bancrofti is the only filarial worm that Anopheles species are capable of transmitting (CDC, 2019; WHO, 2010). Opinions have been expressed on the relationship between the populations of these vectors (mosquitoes) and climate change issues (WHO, 2003). Hence, there is a need to predict their future levels of endemism in order to develop an appropriate response plan in the event of a disease outbreak. Biodiversity can be significantly affected by climate change as it can alter species habitats (Buckley \& Jetz, 2007; Sexton et al., 2009). Climate change has been recognised as a major driver of abundance and distributional losses in many species (Araújo et al., 2006; Thomas, 2004). Inadvertently, a shift in the direction of warmer temperatures could have a significant impact on disease dynamics which might lead to serious outbreaks (Harvell et al., 2002; Pounds et al., 2006). An increase in vector-borne diseases is expected due to the imminent migration of humans towards endemic areas (Woodward et al., 2014). The complexity of transmission hosts of vector-borne diseases makes them extremely sensitive to climate change (Parham et al., 2015). Since the vast majority of disease vectors are of arthropod origins (e.g. insects and mites), climate change is expected to cause changes in distribution, density, seasonality and prevalence of diseases (Brooks \& Hoberg, 2007; Kovats et al., 2001; Mills et al., 2010; Rosenthal, 2009). These changes could result in the adaptation of these vectors and hosts leading to new transmission cycles. The prevalence of vector-borne diseases is strongly linked to the population of such vectors (WHO, 2003). So, there is a need to map the potential distribution of An. gambiae. This will help monitor their disease transmission patterns. In addition, vector-borne diseases of arthropod origin are predicted to increase due to climate change in the future (Mills et al., 2010; Rosenthal, 2009). This research aims to map out the potential distribution and climatic suitability of An. gambiae under the present-day and future conditions. Information on the pattern of spatial distribution of vectors is crucial for assessing the risk of disease transmission in a different region. Predicting the occurrence of a vector in specific regions is therefore a challenge for many disease control programmes to more effectively plan and implement control interventions and adaptation measures (Carvalho et al., 2017).

\section{Materials and methods}

\section{Study area}

The study was investigated in Southwest Nigeria one of the six geopolitical zones of the country (Fig. 1). States in this region include Ekiti, Lagos, Ogun, Ondo, Osun and Oyo. It is geographically located between longitude $2^{\circ} 31^{\prime}$ and $6^{\circ} 00^{\prime}$ East and Latitude $6^{\circ} 2^{\prime}$ and $8^{\circ} 37^{\prime} \mathrm{N}$ (Agboola, 1979 ) with a total land area of approximately $79,665 \mathrm{~km}^{2}$. It shares boundaries with Edo and Delta states, Kwara and Kogi states, the Republic of Benin and the Gulf of 


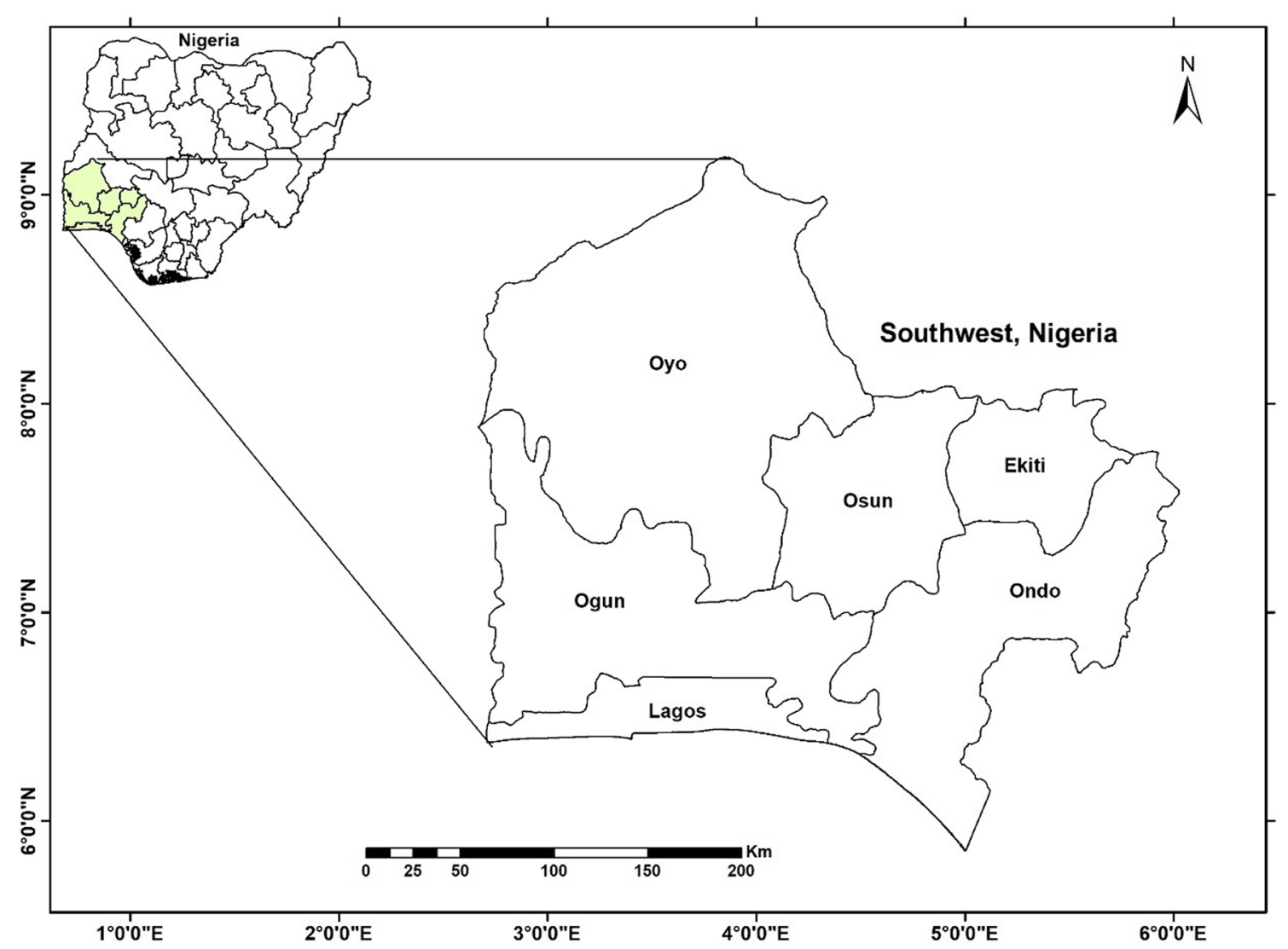

Fig. 1 Map of Southwest Nigeria

Guinea to the east, north, west and south, respectively (Faleyimu et al., 2013). Southwest Nigeria is characterised by a tropical climate of two seasons, namely wet and dry seasons with temperatures ranging from 21 to $34{ }^{\circ} \mathrm{C}$ and annual rainfall ranging from 150 to $3000 \mathrm{~mm}$ (Faleyimu et al., 2013). The vegetation cover of this region consists of freshwater swamps and mangrove forests on the belt, with the lowland part of the forest stretching inland to Ogun and some part of Ondo state, while the secondary forest is towards the northern boundary of the southern Savannah (Agboola, 1979).

\section{Species record data collection}

Data for the species record were obtained from scientific literature published between 1990 and 2019. Literature searches were conducted using online databases such as Google, Google Scholar, Researchgate, Plosone, PubMed, Scopus, Walter Reed Biosystematics Unit Culicidae Systematic Literature Database search engine (VectorMap projects). The search terms used include Southwest Nigeria, mosquito, Anopheles gambiae, Ondo, Lagos, Ekiti, Ogun, Oyo, Osun and their combinations. All articles containing information on the records of An. gambiae were examined for species records. A further search was carried out on references cited in the identified articles which were presumed to have additional information on species records. Articles without records of collection were discarded. Collated occurrence data were then cross-checked with Anopheles vector database in Nigeria compiled by Okorie et al. (2011) and the Global Biodiversity Information Facility (GBIF) online repository to ensure that no data were missed. Duplicate records reported by different authors were reduced to one. The data collected from the articles included state, locality, latitude and longitude.

\section{Data georeferencing and cleaning}

Species records with coordinates were checked for correctness to ensure that they are properly linked to their respective collection sites. This was done using Google Maps (https://www.maps.google.com). Also, species records without coordinates but with community-level collection sites were assigned coordinates by obtaining them from Google Maps. This was done by searching for the name or description of the collection sites from the record source. Collection sites at the state and local 
government levels were excluded from data to avoid the use of low-precision species record. Species records earlier than 1990 were also discarded. All species record coordinates were then converted to a decimal degree format. The data coordinates observed to appear more than once were reduced to one. The data for the occurrence record were compiled using Microsoft Excel spreadsheet package, and it is provided in the attached Additional file 1.

\section{Environmental variables used}

Bioclimatic layers consisting of 19 variables (see Table 1) for the present-day and future conditions were obtained from WorldClim database version 1.4. This provides information about climate layers from weather station data between 1950 and 2000 (Hijmans et al., 2005) for present-day niche model and downscaled cumulative impact monitoring program 5 (CIMP5) database consisting of future conditions (average for 2041-2060). The future conditions used for this study were based on two General Circulation Models (GCMs), namely Community Climate System Model 4 (CCSM4) and Geophysical Fluid Dynamics Laboratory Model 3 (GFDL-CM3) in two representative concentration pathways (RCP 2.6 and RCP 8.5), where RCP 2.6 represents a low greenhouse gas (GHG) concentration scenario and RCP 8.5 represents a high level of GHGs in the future (Stocker et al., 2013).

Table 1 Environmental variables used for the study

\begin{tabular}{ll}
\hline Variable & Interpretation \\
\hline Bio 1 & Annual Mean Temperature \\
Bio 2 & Mean Diurnal Range (Mean of monthly (max \\
& temp-min temp)) \\
Bio 3 & Isothermality (BIO2/BIO7) $\left({ }^{*} 100\right)$ \\
Bio 4 & Temperature Seasonality (standard deviation *100) \\
Bio 5 & Max Temperature of Warmest Month \\
Bio 6 & Min Temperature of Coldest Month \\
Bio 7 & Temperature Annual Range (BIO5-BIO6) \\
Bio 8 & Mean Temperature of Wettest Quarter \\
Bio 9 & Mean Temperature of Driest Quarter \\
Bio 10 & Mean Temperature of Warmest Quarter \\
Bio 11 & Mean Temperature of Coldest Quarter \\
Bio 12 & Annual Precipitation \\
Bio 13 & Precipitation of Wettest Month \\
Bio 14 & Precipitation of Driest Month \\
Bio 15 & Precipitation Seasonality (Coefficient of Variation) \\
Bio 16 & Precipitation of Wettest Quarter \\
Bio 17 & Precipitation of Driest Quarter \\
Bio 18 & Precipitation of Warmest Quarter \\
Bio 19 & Precipitation of Coldest Quarter \\
\hline
\end{tabular}

\section{Model analysis and mapping}

The bioclimatic layers used for this study were modified with ArcMap (version 10.5) by clipping them to the same extent using the shapefile of the study area as a template. The correlation function in the desktop version of ENMtools (version 1.4.4) was used to check for correlation between clipped bioclimatic variables used in this study (Warren et al., 2010). When two or more interacting variables were observed to have strong correlations $(r \geq 0.80)$, only one of them is used removing the others or both retained if they are vital to the mosquito species survival (Rödder et al., 2009; Synes \& Osborne, 2011; Aguilar \& Lado, 2012; Alkishe et al., 2020). The resulting bioclimatic variables were used for the niche model.

A subset of species that are at least $10 \mathrm{~km}$ apart from the nearest record were randomly selected to reduce spatial auto-correlation using the spThin package on the $\mathrm{R}$ platform (Aiello-Lammens et al., 2015). Background points for pseudo-absence records were generated by stacking environmental variables together to generate potential background points. This was done on the $\mathrm{R}$ platform using raster and dismo packages (Hijmans et al., 2016, 2017; R Core Team, 2017). A fraction of the potential background point, which was $10 \times$ higher than the species occurrence record, was used for model calibration. The ENMEval package (version 0.3.0) on the R platform was used to determine the best settings for optimal model niche modelling in the MaxEnt software (Muscarella et al., 2014). The random cross-validation method and 10 cross-validation folds were used to run the evaluation. Corrected Akaike Information Criterion (AICc) was used to evaluate the complexity of the model (Warren \& Seifert, 2011). Out of the generated result, the model setting with the lowest Delta AICc value (between 0 and 2) was chosen and implemented in MaxEnt (version 3.4.0) to produce the model output (Phillips \& Dudík, 2008). The future condition models were generated for each RCPs under the two GCMs used to examine their individual potential distribution. Model performance was evaluated using partial receiver operating characteristics ( $p$ ROC) statistics applied to the $50 \%$ subset of occurrences left out prior to model calibration for testing. This approach has been used as a means of eliminating possible errors associated with traditional ROCs provided in MaxEnt outputs Peterson et al., 2008; Lobo et al., 2008). PartialROC was calculated using the PartialROC function available on the Ntbox platform (Osorio-Olvera et al., 2018). The mean of iterations was used to estimate the ecological niche model output. This output was then used to produce the suitability map. The MaxEnt output was classified in ArcMap into areas of very low $(0-0.1)$, low $(>0.1-0.2)$, moderate $(>0.2-0.4)$, high 
(>0.4-0.6), and very high $(>0.6)$ using natural breaks in the symbology tools to produce the habitat suitability model picture (Sallam et al., 2016). The percentage area occupied by each class was calculated using the cell numbers from their attribute tables. Uncertainty maps were produced by calculating the standard deviation of pixel values from model outputs generated (de Oliveira et al., 2018). The uncertainty levels were classified as low (0.00-0.03), moderate $(>0.03-0.05)$ and high $(>0.05)$ using the standard deviation values. All data from this study was projected on a spatial resolution of $2.5 \mathrm{~min}(\approx 5 \mathrm{~km})$.

\section{Results}

Point presence of An. gambiae in Southwestern Nigeria

The database compiled for this study were about 99 presence records for An. gambiae associated with geographical coordinates after data cleaning (Additional file 1). After distance filtering, 55 unique occurrence data were used for model calibration (Fig. 2). There are some locations in the study area that need sampling and are represented by red line shapes.
Environmental variables used for the niche model calibration of An. gambiae in Southwestern Nigeria

The correlation analysis conducted reduced the bioclimatic variables to 8 that were eventually used for model calibration. These variables are Bio1 (Annual mean temperature), Bio2 (Mean diurnal range), Bio3 (Isothermality), Bio5 (Maximum Temperature of Warmest Month), Bio6 (Minimum temperature of coldest month), Bio7 (Temperature annual range), Bio12 (Annual precipitation), Bio13 (Precipitation of wettest month), Bio14 (Precipitation of driest month), Bio15 (Precipitation seasonality).

\section{Climatic suitability model for An. gambiae}

The potential distribution under present-day conditions for An. gambiae in Fig. 3a showed that a large portion of Southwest Nigeria can support the population of this species. This model revealed that $81.71 \%\left(65,090.53 \mathrm{~km}^{2}\right)$ of the study area was climatically suitable for An. gambiae (Table 2). The model prediction performed better than random outcomes based on the $p$ ROC test in which the mean AUC ratio was $1.45(p<0.001)$.

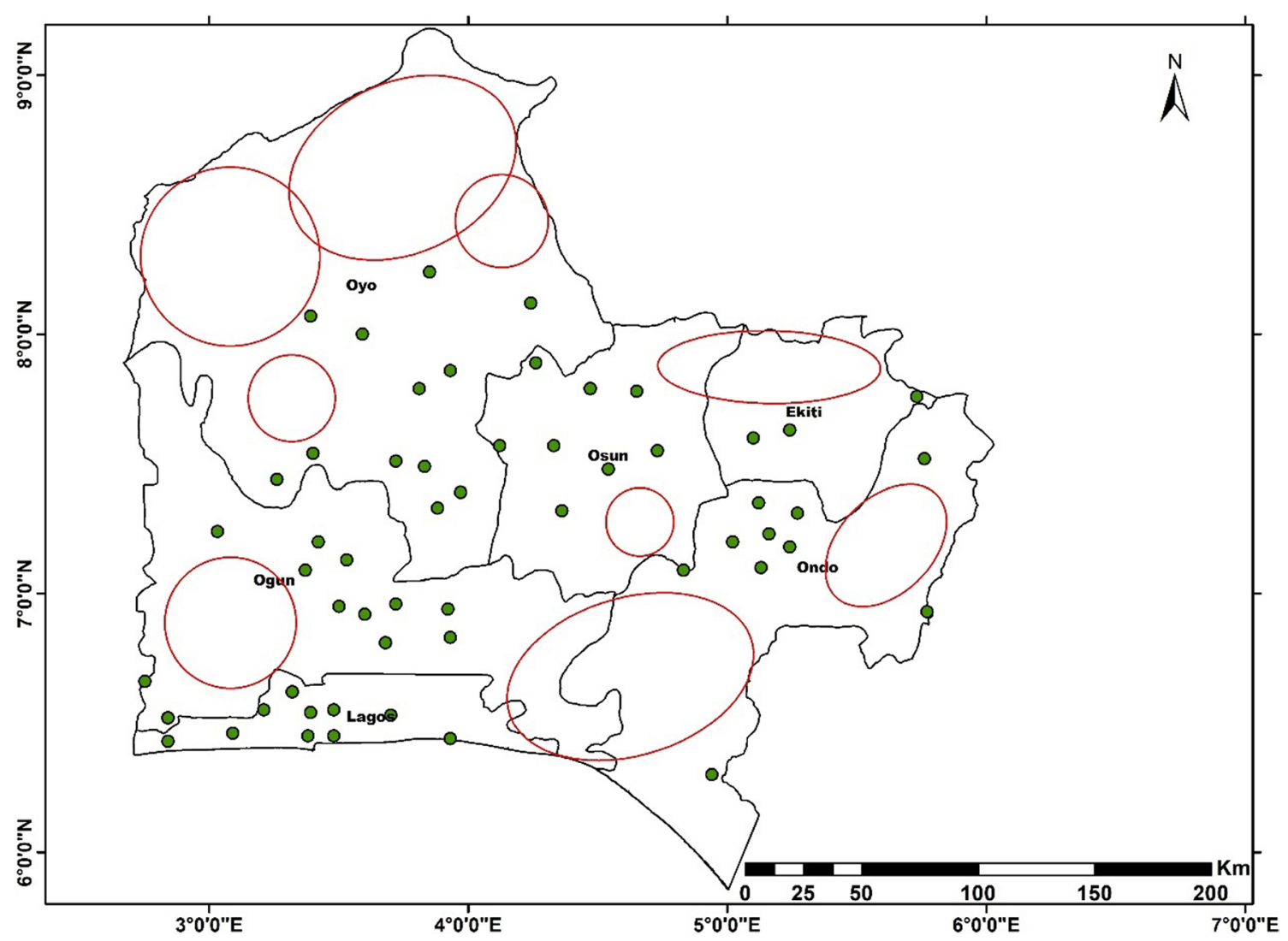

Fig. 2 Occurrence record (green dots) of An. gambiae used for model calibration and areas needing further sampling (red line shapes) 

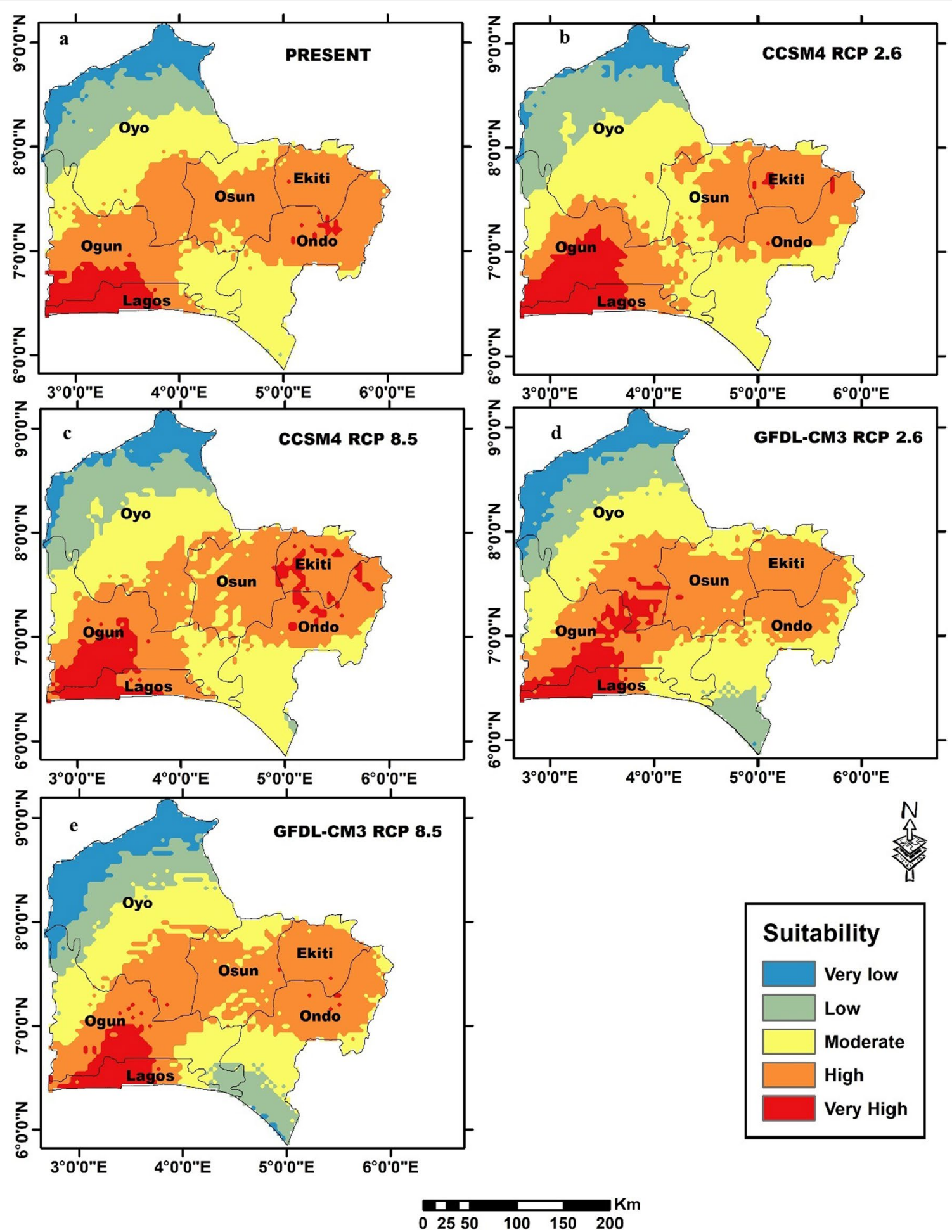

Fig. 3 Model picture of climatic suitability of present-day and future conditions for An. Gambiae

Projecting the An. gambiae model to future conditions showed similarity in the overall pattern of distributional to that under present-day conditions (Fig. 3b-e).
However, the two GCMs used in this study presented conflicting levels of suitability for the species compared to present-day conditions (Table 2). The CCSM4 models 
Table 2 Percentage climatic suitability of present-day and future conditions for An. gambiae

\begin{tabular}{lccccc}
\hline Suitability & \multicolumn{4}{l}{ Percentage area occupied [\%] (Area occupied in Km ${ }^{2}$ ) } & \\
\cline { 2 - 6 } & Present-day & CCSM4 RCP26 & CCSM4 RCP85 & GFDL-CM3 RCP26 & GFDL-CM3 RCP85 \\
\hline Very low & $6.73(5363.76)$ & $4.37(3481.90)$ & $5.88(4682.30)$ & $7.56(6023.24)$ & $9.93(7913.74)$ \\
Low & $11.56(9210.72)$ & $13.86(11,040.71)$ & $11.78(9386.58)$ & $13.58(10,815.45)$ & $13.66(10,881.39)$ \\
Moderate & $32.17(25,631.73)$ & $38.34(30,543.76)$ & $32.70(26,049.40)$ & $32.67(26,027.42)$ & $29.58(23,565.36)$ \\
High & $42.41(33,787.28)$ & $33.64(26,797.41)$ & $40.51(32,270.78)$ & $37.91(30,204.11)$ & $40.84(32,534.27)$ \\
Very high & $7.12(5671.51)$ & $9.79(7801.22)$ & $9.13(7276.25)$ & $8.28(6594.78)$ & $5.99(4770.23)$ \\
Unsuitable (Very low to Low) & $18.29(14,574.47)$ & $18.29(14,574.47)$ & $17.66(14,068.87)$ & $21.14(16,838.68)$ & $23.59(18,795.14)$ \\
Suitable (Moderate to Very high) & $81.71(65,090.53)$ & $81.77(65,142.39)$ & $82.34(65,596.13)$ & $78.86(62,826.32)$ & $76.41(60,869.86)$ \\
\hline
\end{tabular}

indicated a slight increase in both RCPs with 2.5 and 8.5 having 81.77 and $82.34 \%$ suitability, respectively. It was a reverse scenario for the GFDL-CM3 models as RCPs 2.5 and 8.5 had 78.86 and $76.86 \%$ suitability correspondingly which suggested a decrease from the present-day value.

Lagos and Ogun state had more areas with very high suitability for An. gambiae compared to other states across all the models (Fig. 3).

The level of uncertainty for each model is shown in Fig. 4. This indicated that larger areas had low levels of uncertainty across different models generated in this study.

\section{Discussion}

This study collated the occurrence data set for An. gambiae species in southwest Nigeria and provided detailed maps of their potential geographic distribution under present-day and future climatic conditions. The essence of modelling their future distribution was to provide an insight into the potential distribution variability that could exist in comparison with present-day conditions. The model pictures described the current distribution of An. gambiae and also anticipated possible changes in the range of the species under future conditions. This will help concerned stakeholders identify risk areas where the diseases they transmit may be established with the availability of infection sources through human dynamics. The $p$ ROC test carried out on the models generated from this study showed that they performed better than random. Uncertainty mapping was done due to the spatial variability associated with different GCMs and ENMs methods (Diniz-Filho et al., 2009; Buisson et al., 2010; Carvalho et al., 2017). The uncertainty mapping provided more confidence in the areas predicted as environmentally suitable by the models.

However, the distribution of this Anopheles mosquito species is as a result of the relationship that exists between factors such as climatic factors, landforms, soil types and the human settlement patterns of different ecological zones (Moffett et al., 2007; Tolulope, 2014; Siteti et al., 2016). However, this present study focused only on how climatic factors could affect their distribution pattern. Across Southwest Nigeria, the potential distribution of An. gambiae generated from the presentday scenario seems to be far-reaching. This is because its overall distribution and climatic suitability cover more than two-thirds of the study area. This finding was similar to that reported by Akpan et al. (2018). It is very imperative to know that areas with high suitability and low distribution density of An. gambiae may have a serious likelihood of experiencing widespread prevalence alongside high distribution density, species migration and invasion (Peterson, 2009). Previous reports by Lindsay et al. (1998), Onyabe and Conn (2001), Moffett et al. (2007) and Kulkarni et al. (2010) suggest that the range, relative abundance and ecological adaptability of $A n$. gambiae are significantly influenced by climate seasonality, random temporal fluctuations, annual precipitation. Accordingly, their reports corroborate with the findings of this study because all the factors they mentioned played one role or the other in determining the distribution of the species in the study area.

The two GCMs used in this study presented conflicting levels of suitability for the species compared to the present-day conditions. The CCSM4 models showed a slight increase in suitability while the GFDL-CM3 models suggested a decrease from the present-day value. However, they both indicated continued climate suitability under future conditions. The latter model (GFDLCM3) is in agreement with the submissions of Drake and Bier (2014) and Tonnang et al. (2014). Their studies predict contractions in the distribution area of Anopheles species in West African countries. However, the overall contraction of the vector's full range could mistakenly suggest less exposure to vector-borne diseases with climate change (Carvalho et al., 2017). Likewise, the association with human distribution demonstrates the need for necessary precautions when interpreting 


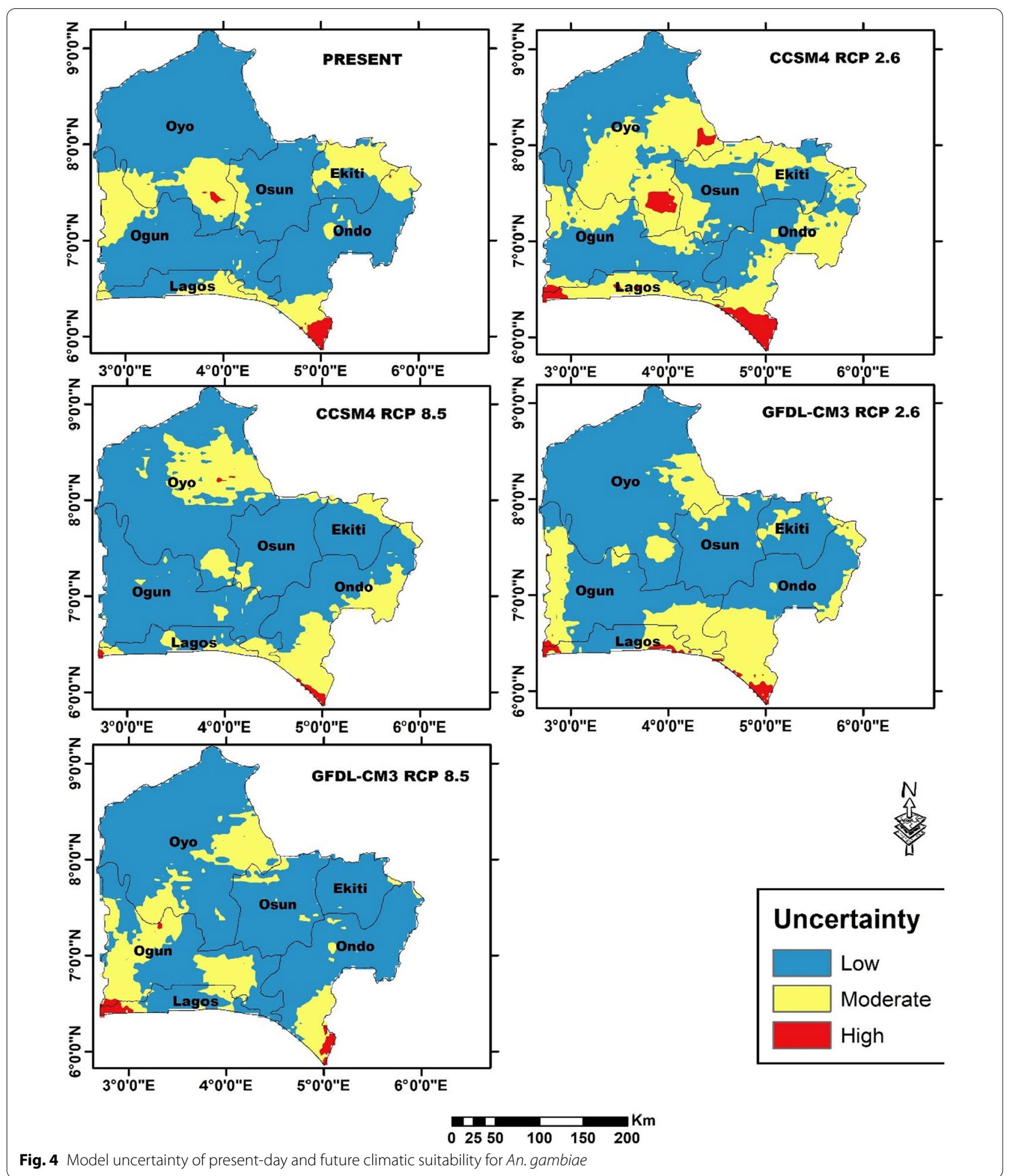

vector ENM predictions. The occurrence of vectors by itself does not necessarily imply a higher risk of disease transmission and a closer look at other risk factors is required. In addition to previously mentioned factors, land cover, land use and human population also contribute to the distribution of Anopheles species and incidence of malaria (Wiebe et al., 2017; Zohdy et al., 2016). The lack of futuristic land cover, land use and 
human population data in a way limits the scope of the models generated by this study. Also, the lack of sampling for An. gambiae in some areas may affect the precision of these model.

\section{Conclusion}

The assessment of the models generated by this study showed that vast area Southwest Nigeria will continue to be climatically suitable for the population of $A n$. gambiae species under projected future conditions. Therefore, the outcome of this model can be used to forecast probable cases of diseases that may be vectored by the species modelled in this study. This will go a long way towards informing the appropriate authorities to design effective response plan and control measures to combat the prevalence of the diseases transmitted by An. gambiae in the future. For more robust ENMs, further studies geared towards simulated datasets for future land cover, land use and human population should be carried out. Also, more areas of the region need to be sampled for better prediction.

\author{
Abbreviations \\ ENM: Ecological Niche modelling; GIS: Geographic information systems; \\ CIMP5: Cumulative impact monitoring program 5; CCSM4: Community \\ climate system model 4; GFDL-CM3: Geophysical fluid dynamics laboratory- \\ climate model 3; RCPs: Representative concentration pathways; ROC: Receiver \\ operating characteristic; AUC: Area under the ROC curve; $p$ ROC: Partial receiver \\ operating characteristic.
}

\section{Supplementary Information}

The online version contains supplementary material available at https://doi. org/10.1186/s41936-021-00261-8.

Additional file 1. Anopheles gambiae occurrence dataset used.

\section{Acknowledgements}

The authors thank Prof. C.O. Adedire, Dr J.A. Adeyemi, Dr O. A Alabi, Mr C.C. Oliseh and Mr E. T. Obimakinde in the Department of Biology and Dr S.O. Oladejo in the Department of Remote Sensing and Geoinformatics all of the Federal University of Technology, Akure, Nigeria, for their priceless advice and support during this research.

\section{Authors' contributions}

This research work was carried out in collaboration among all authors. KDI conceived the idea; 100 and TEA designed the experimental procedure for the study. 100 collected data on experimental procedure and carried out the data analysis. BWA did the manuscript reviewing; KDI and IOO implemented the references search and manuscript draft. All authors read and approved the final manuscript.

\section{Funding}

The research work was self-funded.

\section{Availability of data and materials}

Research data are available in the attached Additional file 1.

\section{Declarations}

Ethics approval and consent to participate

Not applicable.

\section{Consent for publication}

Not applicable.

\section{Competing interests}

The authors declare that they have no competing interests.

\section{Author details}

${ }^{1}$ Environmental Biology and Public Health Unit, Department of Biology, School of Science, Federal University of Technology, Ondo State, P. M. B. 704, Akure, Nigeria. ${ }^{2}$ Applied Entomology Unit, Department of Biology, School of Science, Federal University of Technology, Ondo State, P. M. B. 704, Akure, Nigeria.

${ }^{3}$ Centre of Conservation Medicine and Ecological Safety, Northeast Forestry University, Harbin, People's Republic of China.

Received: 4 May 2020 Accepted: 11 November 2021

Published online: 22 November 2021

\section{References}

Abose, T., Yeebiyo, Y., Olana, D., Alamirew, D., Beyene, Y., Regassa, L., \& Mengesha, A. (1998). Re-orientation and definition of the role of malaria vectorcontrol in Ethiopia: The epidemiology and control of malaria with special emphasis on the distribution, behaviour and susceptibility of insecticides of anopheline vectors and chloroquine resistance in Zwai, Central Ethiopia and other areas (p. 31). World Health Organization.

Agboola, S. A. (1979). An agricultural Atlas of Nigeria (p. 51). Oxford University Press.

Aguilar, M., \& Lado, C. (2012). Ecological niche models reveal the importance of climate variability for the biogeography of protosteloid amoebae. The ISME Journal, 6(8), 1506-1514.

Aiello-Lammens, M. E., Boria, R. A., Radosavljevic, A., Vilela, B., \& Anderson, R. P. (2015). spThin: An R package for spatial thinning of species occurrence records for use in ecological niche models. Ecography, 38(5), 541-545.

Akpan, G. E., Adepoju, K. A., Oladosu, O. R., \& Adelabu, S. A. (2018). Dominant malaria vector species in Nigeria: Modelling potential distribution of Anopheles gambiae sensu lato and its siblings with MaxEnt. PLOS ONE, 13(10), e0204233.

Alkishe, A., Cobos, M. E., Peterson, A. T., \& Samy, A. M. (2020). Recognizing sources of uncertainty in disease vector ecological niche models: An example with the tick Rhipicephalus sanguineus sensu lato. Perspectives in Ecology and Conservation.

Anupam, G., Nandita, C., \& Goutam, C. (2012). Plant extracts as potential mosquito larvicides. Indian Journal of Medical Research, 135, 581-598.

Araújo, M. B., Thuiller, W., \& Pearson, R. G. (2006). Climate warming and the decline of amphibians and reptiles in Europe. Journal of Biogeography, 33(10), 1712-1728.

Brooks, D. R., \& Hoberg, E. P. (2007). How will global climate change affect parasite-host assemblages? Trends in Parasitology, 23(12), 571-574.

Brown, J. H., Mehlman, D. W., \& Stevens, G. C. (1995). Spatial variation in abundance. Ecology, 76(7), 2028-2043.

Buckley, L. B., \& Jetz, W. (2007). Environmental and historical constraints on global patterns of amphibian richness. Proceedings of the Royal Society $b$ : Biological Sciences, 274(1614), 1167-1173.

Buisson, L., Thuiller, W., Casajus, N., Lek, S., \& Grenouillet, G. (2010). Uncertainty in ensemble forecasting of species distribution. Global Change Biology, 16(4), 1145-1157.

Carvalho, B. M., Rangel, E. F., \& Vale, M. M. (2017). Evaluation of the impacts of climate change on disease vectors through ecological niche modelling. Bulletin of Entomological Research, 107(4), 419-430.

CDC (2019). Lymphatic filariasis. Retrieved November 13, 2019 from, https:// www.cdc.gov/parasites/lymphaticfilariasis/.

de Oliveira, E. F., Galati, E. A. B., de Oliveira, A. G., Rangel, E. F., \& de Carvalho, B. M. (2018). Ecological niche modelling and predicted geographic 
distribution of Lutzomyia cruzi, vector of Leishmania infantum in South America. PLoS Neglected Tropical Diseases, 12(7), e0006684.

Diniz-Filho, J. A. F., Mauricio Bini, L., Fernando Rangel, T., Loyola, R. D., Hof, C., Nogués-Bravo, D., \& Araújo, M. B. (2009). Partitioning and mapping uncertainties in ensembles of forecasts of species turnover under climate change. Ecography, 32(6), 897-906.

Drake, J. M., \& Beier, J. C. (2014). Ecological niche and potential distribution of Anopheles arabiensis in Africa in 2050. Malaria Journal, 13(1), 213.

Elith, J., Graham, C. H., Anderson, R. P., Dudik, M., Ferrier, S., Guisan, A., Hijmans, R. J., Huettmann, F., Leathwick, J. R., Lehmann, A., Li, J., Lohmann, L. G., Loiselle, B. A., Manion, G., Moritz, C., Nakamura, M., Nakazawa, Y., Overton, J. M., Peterson, A. T., ... Zimmermann, N. E. (2006). Novel methods improve prediction of species' distributions from occurrence data. Ecography, 29, 129-151.

Faleyimu, O. I., Agbeja, B. O., \& Akinyemi, O. (2013). State of forest regeneration in Southwest Nigeria. African Journal of Agricultural Research, 8(26), 3381-3383.

Grinnell, J. (1917). Field tests of theories concerning distributional control. The American Naturalist, 51, 115-128.

Guisan, A., \& Zimmermann, N. E. (2000). Predictive habitat distribution models in ecology. Ecological Modelling, 135(2-3), 147-186.

Harrison, S. (1997). How natural habitat patchiness affects the distribution of diversity in Californian serpentine chaparral. Ecology, 78(6), 1898-1906.

Harvell, C. D., Mitchell, C. E., Ward, J. R., Altizer, S., Dobson, A. P., Ostfeld, R. S., \& Samuel, M. D. (2002). Climate warming and disease risks for terrestrial and marine biota. Science, 296(5576), 2158-2162.

Hawkins, B. A., Field, R., Cornell, H. V., Currie, D. J., Guégan, J. F., Kaufman, D. M. Kerr, J. T., Mittelbach, G. G., Oberdorff, T., O'Brien, E. M., \& Porter, E. E. (2003). Energy, water, and broad-scale geographic patterns of species richness. Ecology, 84(12), 3105-3117.

Hijmans, R. J., Phillips, S., Leathwick, J., \& Elith, J. (2016). dismo: Species distribution modeling. R package version 1.0-15. Retrieved July 15, 2019, from, https://CRAN.R-project.org/package $=$ dismo.

Hijmans, R. J., van Etten, J., Cheng, J., Mattiuzzi, M., Sumner, M., \& Jonathan, A. (2017). raster: Geographic Data Analysis and Modeling. R package version 2.6-7. Retrieved July 15, 2019 from, https://CRAN.R-project.org/packa ge $=$ raster.

Hijmans, R. J., Cameron, S. E., Parra, J. L., Jones, P. G., \& Jarvis, A. (2005). Very high-resolution interpolated climate surfaces for global land areas. International Journal of Climatology, 25, 1965-1978.

Kovats, R. S., Campbell-Lendrum, D. H., Mcmichael, A. J., Woodward, A., \& Cox, J. H. (2001). Early effects of climate change: Do they include changes in vector-borne diseases? Philosophical Transactions of the Royal Society London B, 356, 1057-1068.

Kremen, C., Cameron, A., Moilanen, A., Phillips, S. J., Thomas, C. D., Beentje, H., Dransfield, J., Fisher, B. L., Glaw, F., Good, T. C., \& Harper, G. J. (2008). Aligning conservation priorities across taxa in Madagascar with highresolution planning tools. Science, 320(5873), 222-226.

Kulkarni, M. A., Desrochers, R. E., \& Kerr, J. T. (2010). High resolution niche models of malaria vectors in northern Tanzania: A new capacity to predict malaria risk? PLOS ONE, 5(2), e9396.

Lestina, J., Cook, M., Kumar, S., Morisette, J., Ode, P. J., \& Peairs, F. (2016). MODIS imagery improves pest risk assessment: A case study of wheat stem sawfly (Cephus cinctus, hymenoptera: Cephidae) in Colorado, USA. Environmental Entomology, 45(6), 1343-1351.

Lindsay, S. W., Parson, L., \& Thomas, C. J. (1998). Mapping the range and relative abundance of the two principal African malaria vectors, Anopheles gambiae sensu stricto and An. arabiensis, using climate data. Proceedings of the Royal Society of London. Series B: Biological Sciences, 265(1399), 847-854.

Lobo, J. M., Jiménez-Valverde, A., \& Real, R. (2008). AUC: A misleading measure of the performance of predictive distribution models. Global Ecology and Biogeography, 17(2), 145-151.

Mills, J. N., Gage, K. L., \& Khan, A. S. (2010). Potential influence of climate change on vector-borne and zoonotic diseases: A review and proposed research plan. Environmental Health Perspectives, 118(11), 1507-1514.

Moffett, A., Shackelford, N., \& Sarkar, S. (2007). Malaria in Africa: vector species' niche models and relative risk maps. PLoS One, 2(9), e824.

Muscarella, R., Galante, P. J., Soley-Guardia, M., Boria, R. A., Kass, J. M., Uriarte, M., \& Anderson, R. P. (2014). ENM eval: An R package for conducting spatially independent evaluations and estimating optimal model complexity for
Maxent ecological niche models. Methods in Ecology and Evolution, 5(11), $1198-1205$.

Okorie, P. N., McKenzie, F. E., Ademowo, O. G., Bockarie, M., \& Kelly-Hope, L. (2011). Nigeria Anopheles vector database: an overview of 100 years' research. PLos ONE, 6(12), e28347.

Onyabe, D. Y., \& Conn, J. E. (2001). The distribution of two major malaria vectors, Anopheles gambiae and Anopheles arabiensis, Nigeria. Memórias Do Instituto Oswaldo Cruz, 96(8), 1081-1084.

Osorio-Olvera, L., Vijay, B., Narayani, B., Soberón, J., \& Falconi, M. (2018). Ntbox: From getting biodiversity data to evaluating species distributions models in a friendly GUI environment. R package version 0.2. 5.4.

Parham, P. E., Waldock, J., Christophides, G. K., Hemming, D., Agusto, F., Evans, K. J., Feffermann, N., Gaff, H., Gumel, A., LaDeau, S., Lenhart, S., Mickens, R. E., Naumova, E. N., Ostfeld, R. S., Ready, P. D., Thomas, M. B., Velasco-Hernandez, J., \& Michael, E. (2015). Climate, environmental and socio-economic change: Weighing up the balance in vector-borne disease transmission. Philosophical Transactions of the Royal Society B, 370, 20130551.

Peterson, A. T. (2006). Ecological Niche modeling and spatial patterns of disease transmission. Emerging Infectious Diseases, 12, 1822-1826.

Peterson, A. T. (2009). Shifting suitability for malaria vectors across Africa with warming climates. BMC Infectious Diseases, 9(1), 59.

Peterson, A. T., Papeş, M., \& Soberón, J. (2008). Rethinking receiver operating characteristic analysis applications in ecological niche modeling. Ecological Modelling, 213(1), 63-72.

Peterson, A. T., Soberón, J., \& Sánchez-Cordero, V. (1999). Conservatism of ecological niches in evolutionary time. Science, 285(5431), 1265-1267.

Phillips, S. J., \& Dudík, M. (2008). Modeling of species distributions with Maxent: New extensions and a comprehensive evaluation. Ecography, 31(2), $161-175$.

Pounds, J. A., Bustamante, M. R., Coloma, L. A., Consuegra, J. A., Fogden, M. P., Foster, P. N., La Marca, E., Masters, K. L., Merino-Viteri, A., Puschendorf, R., \& Ron, S. R. (2006). Widespread amphibian extinctions from epidemic disease driven by global warming. Nature, 439(7073), 161.

R Core Team. (2017). R: A Language and Environment for Statistical Computing. R Foundation for Statistical Computing, Vienna, Austria.

Rödder, D., Schmidtlein, S., Veith, M., \& Lötters, S. (2009). Alien invasive slider turtle in unpredicted habitat: A matter of niche shift or of predictors studied?. PLOS ONE, 4(11), e7843.

Rosenthal, J. (2009). Climate change and the geographical distribution of infectious diseases. EcoHealth, 6(4), 189-495.

Sallam, M. F., Xue, R. D., Pereira, R. M., \& Koehler, P. G. (2016). Ecological niche modeling of mosquito vectors of West Nile virus in St. John's County, Florida, USA. Parasites and Vectors, 9(1), 371.

Sexton, J. P., McIntyre, P. J., Angert, A. L., \& Rice, K. J. (2009). Evolution and ecology of species range limits. Annual Review of Ecology, Evolution, and Systematics, 40, 415-436.

Siteti, M. C., Injete, S. D., \& Wanyonyi, W. A. (2016). Malaria parasite species prevalence and transmission dynamics at selected sites in the Western highlands of Kenya. CHRISMED Journal of Health and Research, 3(1), 45.

Stocker, T. F., Qin, D., Plattner, G. K., Tignor, M., Allen, S. K., Boschung, J., Nauels, A., Xia, Y., Bex, V. \& Midgley, P. M. (2013). Climate change 2013: The physical science basis. Contribution of working group I to the fifth assessment report of the intergovernmental panel on climate change, 1535.

Synes, N. W., \& Osborne, P. E. (2011). Choice of predictor variables as a source of uncertainty in continental-scale species distribution modelling under climate change. Global Ecology and Biogeography, 20(6), 904-914.

Thomas, C. D. (2004). Extinction risk from climate change. Nature, 427, 145-148.

Tolulope, O. (2014). Spatio-temporal clustering of malaria Morbidity in Nigeria (2004-2008). Journal of Scientific Research, 13, 99-113.

Tonnang, H. E., Tchouassi, D. P., Juarez, H. S., Igweta, L. K., \& Djouaka, R. F. (2014). Zoom in at African country level: Potential climate induced changes in areas of suitability for survival of malaria vectors. International Journal of Health Geographics, 13(1), 12.

Warren, D. L., Glor, R. E., \& Turelli, M. (2010). ENMTools: A toolbox for comparative studies of environmental niche models. Ecography, 33, 607-611.

Warren, D., \& Seifert, S. (2011). Environmental niche modelling in Maxent: The importance of model complexity and the performance of model selection criteria. Ecological Applications, 21, 335-342.

WHO (2003). Climate Change and Human Health - Risk And Responses summary. Retrieved January 7, 2019 from, https://www.who.int/globalchan ge/climate/en/chapter6.pdf. 
WHO (2007). Malaria elimination: A field manual for low and moderate endemic countries. World Health organization, Geneva, Switzerland. Retrieved June 21, 2019 from, http://www.who.init.

WHO (2010). Progress report 2000-2009 and strategic plan 2010-2020 of the global programme to eliminate lymphatic filariasis: halfway towards eliminating lymphatic filariasis (No. WHO/HTM/NTD/PCT/2010.6). World Health Organization (WHO).

WHO (2019b). Lymphatic filariasis. Retrieved November 21, 2019 from, https:// www.who.int/news-room/fact-sheets/detail/lymphatic-filariasis.

WHO (2019a). Malaria. Retrieved November 21, 2019 from, https://www.who. int/news-room/fact-sheets/detail/malaria.

Wiebe, A., Longbottom, J., Gleave, K., Shearer, F. M., Sinka, M. E., Massey, N. C., Cameron, E., Bhatt, S., Gething, P. W., Hemingway, J., \& Smith, D. L. (2017) Geographical distributions of African malaria vector sibling species and evidence for insecticide resistance. Malaria Journal, 16(1), 85.
Woodward, A., Smith, K. R., Campbell-Lendrum, D., Chadee, D. D., Honda, Y., Liu, Q., Olwoch, J., Revich, B., Sauerborn, R., Chafe, Z., Confalonieri, U., \& Haines, A. (2014). Climate change and health: On the latest IPCC report. The Lancet, 383, 1185-1189.

Zohdy, S., Derfus, K., Headrick, E. G., Andrianjafy, M. T., Wright, P. C., \& Gillespie, T. R. (2016). Small-scale land-use variability affects Anopheles spp. distribution and concomitant Plasmodium infection in humans and mosquito vectors in southeastern Madagascar. Malaria Journal, 15, 114. https://doi. org/10.1186/s12936-016-1164-2.

\section{Publisher's Note}

Springer Nature remains neutral with regard to jurisdictional claims in published maps and institutional affiliations.

\section{Submit your manuscript to a SpringerOpen ${ }^{\circ}$ journal and benefit from:}

- Convenient online submission

- Rigorous peer review

- Open access: articles freely available online

- High visibility within the field

- Retaining the copyright to your article

Submit your next manuscript at $\boldsymbol{\nabla}$ springeropen.com 